\section{TURISMO E PREÇOS}

\section{Juarez Rizzieri”}

RESUMO: Análise de aspectos da formação dos preços nos centros turísticos e sua possivel contribuição ao processo inflacionário, abordando: consumo das atividades turísticas em relação ao consumo total da econonia; variaçóes nos custos de vida nos centros turísticos en função da rigidez da oferta, no que tange à mobilidade geográfica de seu produto: implicações distributivas dos benefícios e custos do poder de monopóíio dos conjuntos turísticos; busca da eficiência alocativa de recursos pela expansão das atividades locais de infra-estrutura turística, em resposta aos movimentos sazonais de demanda.

UNITERMOS: Turismo: economia; preços. Turismo e preços: inflação; consumo; oferta; custos e benefícios. Economia: turismo.

ABSTRACT: Analysis of price determination aspects in touristic centers and its possible contribution to the inflationary process regarding: touristic activities consumption versus total economy consumption; cost of thving differentiations in touristic centers as a result of stiffiness in supply re garding geographic instability of its product; distributive implications of the costs and benefits of monopolistic power of touristic resorts; searching of efficiency of allocation of resources through local activities expansion of touristic groundwork, in response to the seasonal stirring of dermand.

KEY WORDS: Totrism: economy; prices. Tourism and prices: inflation consumption; suplly; costs and benefits. Economy: tourism.

\section{INTRODUÇÃO}

O turismo se caracteriza como uma atividade econômica peculiar, não somente porque tem uma extraordinária preferência na escolha das pessoas, mas porque sua oferta, constituída de atrativos naturais e/ou culturais, encontra-se geograficamente localizada, além de apresentar uma demanda flutuante ao longo do ano. Assim o objetivo desse documento é analisar alguns aspectos da formação dos preços nos centros turísticos e sua possível contribuição ao processo inflacionário.

(*) Professor Doutor Depto. de Economia da Faculdade de Economia e Administração da USP Diretor da Fundacão Instituto de Pesquisas Econônicas (FIPE) Coordenador do Indice de Preços an Consumidor (IPC) da FIPE.

End para corresp. FE A TSP Cidade Universit́ri Av. Prof L uciano Guaberto 908 - CEP 05508 - São Paulo - SP - Brasil.
Na primeira parte é apresentado um comentário a respeito da importância do consumo das atividades turísticas em relação ao consumo total da economia, além de obviamente mostrar que importância tem a magnitude do multiplicador de renda gerada por esse tipo de consumo.

Na segunda parte discute-se a importância que tem a mobilidade geográfica dos produtos para explicar as variações nos custos de vida nos centros de turismo, quando estes se encontram sob pressão de demanda temporária ou permanente. De forma semelhante procura-se mostrar como a oferta inelástica dos equipamentos da infra-estrutura turística local pode alterar tais resultados. As implicações distributivas dos benefícios e custos do poder de monopólio dos conjuntos turísticos também são comentadas.

Finalmente, algumas afirmações são feitas sobre a eficiência alocativa dos recursos pela expansão das atividades locais da infra-estrutura turística, a partir de plantas divisíveis, em resposta aos movimentos estacionais da demanda dessa atividade.

\section{CONSUMO DO TURISMO E FORMAÇÃO DOS PREÇOS}

As quantidades consumidas de bens e serviços dos diversos setores da economia brasileira pela atividade de turismo constituem-se em preciosas informações para se ter alguma idéia dos possíveis impactos dessa origem de consumo sobre os preços nos diversos mercados. Infelizmente as informações disponiveis são de 1980, o que limita a análise apenas a critérios de ordem mais qualitativa, conforme dados da Tabela na página seguinte. Observa-se que a proporção do consumo do turismo comparado ao consumo total é relativamente pequena, gravitando em torno de 1,0 a $8,0 \%$, exceto para as atividades diretamente voltadas ao turismo, como transportes de passageiros, hotéis e serviços de apoio ao turismo, onde a participação é maciça.

Desta forma é possível classificar os impactos da demanda de turismo sobre os diversos mercados em dois tipos: aquele conjunto de bens e serviços pertencentes ao primeiro grupo e que se caracteriza por uma oferta plenamente elástica, graças a sua mobilidade ao comércio geográfico; e aquele conjunto do segundo grupo que não se apresenta com mobilidade ao comércio, logo sem chance de ter sua oferta ampliada no curto prazo. É nesse último tipo de mercádo que se pode esperar o início de uma elevação no custo de vida dos centros turísticos, detonado por um acréscimo de demanda de turismo. O sim- 
TABELA - Impacto de consumo e as rendas setoriais devido às atividades de turismo

\begin{tabular}{|c|c|c|}
\hline \multirow[t]{2}{*}{ SETORES } & $\begin{array}{c}\text { Consumo total } \\
\text { do Turisino }\end{array}$ & \multirow{2}{*}{$\begin{array}{c}\text { Multiplicador } \\
\text { Unitúrio } \\
\text { de Rencla }\end{array}$} \\
\hline & $\begin{array}{l}\text { Consumo total } \\
\text { das Famílias }\end{array}$ & \\
\hline 1. Alimentos e Bebidas Elaboradas & 3.15 & 2.59 \\
\hline 2. Máquinas em Geral e Equip. de Transporte & 1.20 & 2.45 \\
\hline 3. Indústria de Móveis & 1,20 & 2.37 \\
\hline 4. Indústria Editorial e Grática & 4.90 & 2.10 \\
\hline 5. Refino de Petróleo & 7.85 & 1.37 \\
\hline 6. Indústria Perfumaria, Sabão e Velas & 2,40 & 2.35 \\
\hline 7. Produtos Têxteis & 1,20 & 2.64 \\
\hline 8. Artigos de Vestuário & 2,13 & 2.61 \\
\hline 9. Calçados & 2,50 & 2,28 \\
\hline 10. Comércio & 3.66 & 1.50 \\
\hline 11. Transporte Rodoviário de Passageiros & 11,68 & 1,67 \\
\hline 12. Transporte Aéreo Doméstico & 71,34 & 1.76 \\
\hline 13. Transporte Aéreo Internacional & 100,00 & 1,79 \\
\hline 14. Comunicações & 12.12 & 1.48 \\
\hline 15. Meios de Hospedagem de 4 a 5 Estrelas & 96.25 & 2.23 \\
\hline 16. Meios de Hospedagem de 1 a 3 Estrelas & 94,99 & 2.23 \\
\hline 17. Outros Meios de Hospedagem & 89,16 & 2.23 \\
\hline 18. Serviços de Alimentaçāo & 14,96 & 2.22 \\
\hline 19. Serviços de Apoio Turístico & 100,00 & 1,27 \\
\hline 20. Recreação & 7.45 & 1,37 \\
\hline 21. Aluguel de Imoveis & 2.77 & 1.30 \\
\hline
\end{tabular}

Fonte: Tabulação Lispecial da FIBGiE - 1980.

ples fato do efeito multiplicador de renda dos gastos do turismo ser maior nas suas atividades meio justifica esse resultado, ou seja, essas tividades apresentam uma grande interface com outros setores na sua àdeia de produção, além obviamente da sua maior capacidade de ajustar preços sob qualquer pressão de demanda. Essas cifras podem ser vistas na segunda coluna da Tabela. Contudo, esse movimento dos preços somente pode induzir um processo inflacionário se a oferta dos produtos não-comercializáveis for ampliada a partir de custos crescentes. Fato esse que vai depender exclusivamente da disponibilidade dos fatores associados ao acréscimo da produção. Aqui cabe uma discussão especial.

Como se sabe, a demanda da infra-estrutura é uma demanda derivada, na maioria das vezes, dos atrativos naturais e/ou culturais geograficamente localizados, o que lhe confere um certo poder de monopólio na formação de seus respectivos preços.

Essa é uma característica do turismo pouco explorada na literatura pertinente. Assim, quanto menos substitutos existirem ao conjunto turístico de referência, maior é o poder de monopólio a ser explorado pelos equipamentos disponíveis de infra-estrutura de apoio ao acesso do objeto do turismo. Contudo uma parte do benefício extraordinário desse poder de fazer preço acima da concorrência é automaticamente transferido para os proprietários dos espaços físicos, que não sāo passíveis de produção. É de se esperar que ao longo do tempo exista uma tendência natural desse poder de monopólio ir desaparecendo para os equipamentos de infra-estrutura turística, uma vez que a sua oferta a longo prazo passa a ser mais concorrencial. Quanto ao conjunto turístico de referência (natural e/ou cultural), na maioria das vezes é apenas possível reduzir seu poder de monopólio, ficando sua eliminação praticamente impossível. Todavia, normalmente ocorre que os atrativos turísticos se constituem em patrimônio público, onde não são explorados os direitos de propriedade, e o setor privado se apropria deles através da exploração dos equipamentos de infra-estrutura, pelo menos enquanto durarem.

O assunto não se esgota aí, pois existem outras implicações do ponto de vista distributivo, quanto aos benefícios e custos do turismo. Normalmente a população que exerce as atividades de turismo são dotadas de um nível de renda mais elevado que a população residentc dos respectivos pontos turísticos. Isso significa que ao crescer a demanda local pelo turismo existe uma valorização de todo o conjunto de lazer, inclusive a infra-estrutura. Beneficiam-se os que cxploram as atividades diretamente voltadas ao turismo, os proprictários de imóveis e as prefeituras locais pela valorização constante do IPTU ou ISS Perdem os moradores cujas atividades estão muito distantes daquelas ligadas à exploração do turismo local. Os elevados níveis dos multiplicadores de renda induzidos pelas átividades do turismo $(2,2.3 \mathrm{conforme}$ dados da Tabela) revelam una grande capacidade de geração de renda dessa atividade, mas é bom lembrar que nem tudo é internalizado na economia local, ou seja, uma parte significativa da demanda é atendida com produtos de fabricação externa. Assim, não basta observar a magnitude dos multiplicadores como um benefício para todos, mas apcnas para aqueles mais diretamente ligados aos serviços de atendimento ao turista. 


\section{QUESTÃO DA INEFICIÊNCIA ALOCATIVA}

A relação entre o consumo de turismo, o nível e a variação dos preços na economia não é tão simples como descrito anteriormente. A análise de formação dos preços, sua variação temporária ou mesmo permanente complica-se à medida que o movimento turístico seja uniforme ou flutuante para os diversos pontos de lazer do território nacional. Quando se trata de um fluxo de turismo permanente, é de se esperar que o acréscimo de demanda seja acompanhado por um adicional equivalente da oferta de bens de serviços, não se observando pressōes sobre o custo de vida nos respectivos locais receptores do turismo. Neste caso está-se falando de bens e serviços, caracterizados por uma oferta plenamente elástica, onde o preço passa a ser determinado pela oferta, e a quantidade, exclusivamente pelo nível de demanda total. O fluxo uniforme de turismo garante uma adequada administração dos estoques dos bens comercializáveis, bem como uma disponibilidade de infra-estrutura turística que impede escassez ou ociosidade, reduzindo-se fortes pressōes sobre os respectivos preços. Isso significa dizer que os produtos com grande mobilidade geográfica tendem a equalizar seus preços, mantendo-se como diferencial apenas os custos de transporte, ao passo que os bens e serviços fora do fluxo de comércio mantêm sua oferta constantemente ajustada ao nível da demanda corrente. Esse último fato apenas não ocorre na presença das fases depressivas da atividade econômica, onde a queda da demanda produz uma ociosidade, caracterizando-se uma ineficiência alocativa.

Essa regra de formação de preços não se aplica aos mercados turísticos que sofrem uma forte flutuação da demanda, dando origem a uma ineficiência alocativa, mesmo que temporária, devido à excassez de oferta nos momentos de "alta estação", ou uma ociosidade nos momentos de "baixa estação" turística. Esse problema complica-se sobremaneira à medida que a oferta se caracterize por uma expansão a partir de "plantas divisíveis ou indivisíveis".

Demanda flutuante e plantas divisíveis é o caso que se aplica à maioria das mercadorias sujeitas ao comércio geográfico, onde o volume de bens ofertados responde muito rapidamente à dimensão da demanda existente e o ajuste é sempre marcadamente nas quantidades, garantindo-lhes maior estabilidade aos preços. Para os bens e serviços relacionados ao equipamento turístico (hospedagem, restaurantes etc.), a situação é um pouco diferente. É evidente que existem algumas soluçōes com expansão da oferta a partir de plantas divisíveis para absorver turistas nas épocas de alta estação. Isto é, dá para transformar uma residência em hospedaria, ou um terraço num móciulo adicional do restaurante... Certamente, não é desse tipo de solução que a inefi. ciência alocativa surge nessas ativiỏades econômicas, mas cia necessidade de investimentos que permitam ampliar a oferta capaz de atender "qualitativamente" aos serviços da demanda do turista. Haverá cxcas. sez nos períodos de excesso de demanda, mas certamente ociosidade nas épocas de baixa estação. Como administrar os preços dos serviços ao longo do ano que engloba ambos os períodos?

Para um bom entendimento da questão torna-se necessária uma adequada especificação dos custos na oferta e das demandas periódicas de alta e baixa estação de turismo.

a) No lado da oferta há dois tipos de custos: custos de operação (b) que englobam principalmente os custos de pessoal, energía etc. considerados evitáveis ou variáveis com o nível de produção, e os custos de capacidade $(B)$ ou fixos, que englobam os imóveis, os equipamentos, a administração etc. Assim, no curto prazo os custos relevantes para a formação dos preços são apenas os operacionais, ao passo que para o longo prazo também devem ser considerados os custos fixos da expansão de capacidade. Para efeito de simplificaçăo admite-se que existem retornos constantes de escala na produção e na expansāe.

b) No íado da demanda deve-se especificar duas demandas independentes entre si no tempo - uma para alta estação e a outra para baixa estação de turismo, tal que:

$\mathrm{Di}=$ Demanda do sub-período i;

$\mathrm{i}$ = número de meses de alta a baixa estação, talvez quatro e oito meses respectivamente. É evidente que nãu se está considerando os feriados e fins de semana;

$\mathrm{Wi}=$ fração do tempo durante o qual a demanda prevalece, no caso $1 / 3$ na alta e $2 / 3$ na baixa.

Desta forma as demandas são denominadas $\mathrm{Da}=(1 / 3) \mathrm{c} \mathrm{Db}=$ $(2 / 3)$, a partir de onde se extrai uma "Demanda Efetiva (DE)" cquivalente à média ponderada, conforme a Figura a seguir.

No caso em análise, os custos marginais (iguais aos médios) de operação permanecem constantes, iguais $a b$, até a produção atingir o limite da capacidade, quando então chega a ser infinito. A planta pode ser eficientemente abastecida apenas em múltiplos dé unidade do pro- 


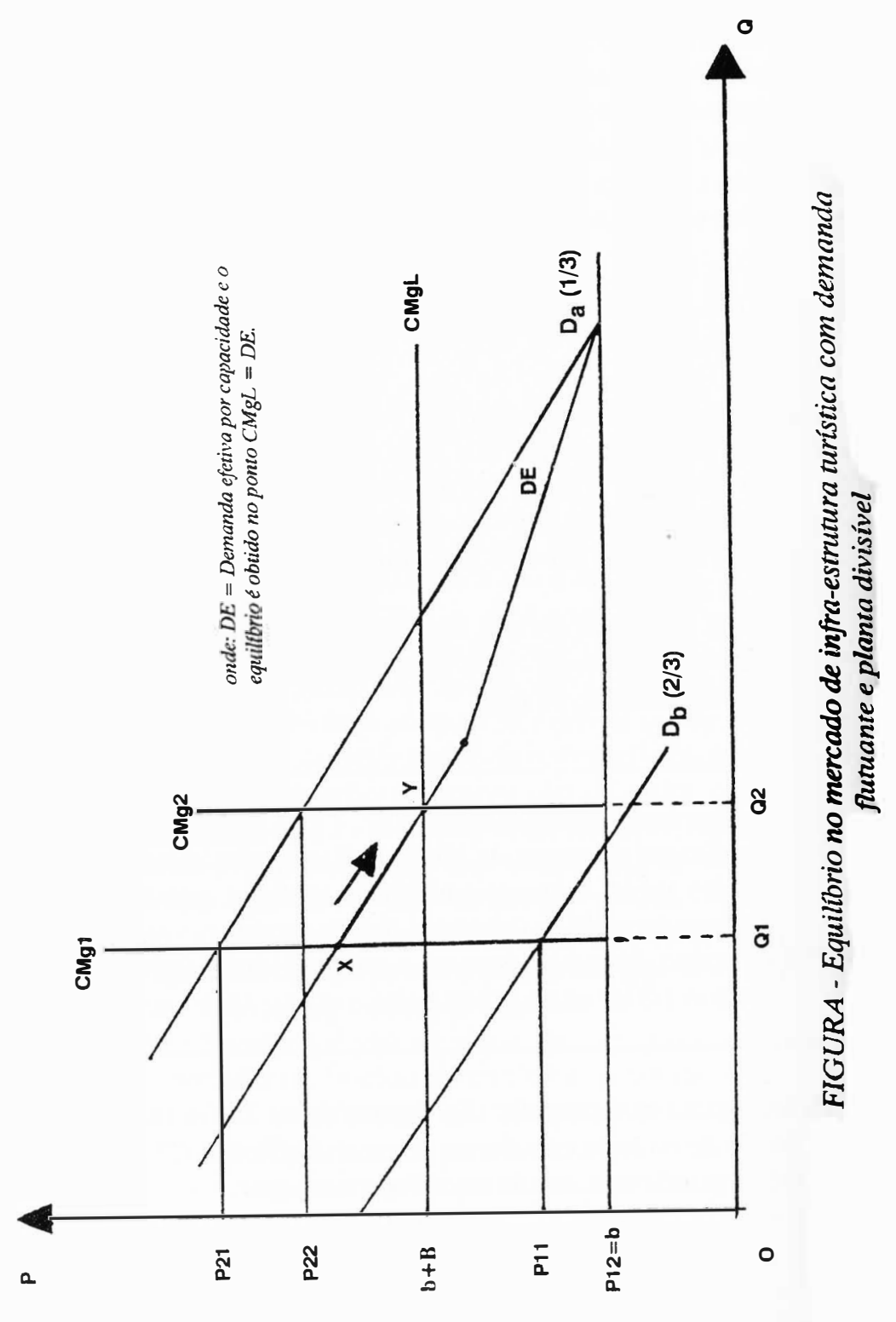

duto de um certo tamanho, como, por exemplo Q1Q2. Logo, na Figura $\mathrm{CMg} 1$ equivale à curva de custo marginal de operação da planta 1 no curto prazo. O $\mathrm{CMg} 2$, da planta $2 \mathrm{e}$, assim, sucessivamente.

A análise mostra que o preço deve exceder o custo marginal de operação em períodos de alta estação turística, porém em períodos de baixa estação o preço deve igualar o custo marginal de operação, como se aplica ao caso P12 e P22, considerando-se a existência das plantas 1 (Q1) e 2 (Q2)

Na ausência da planta 2, os preços P11 e P21 mostram um excesso de demanda permanente, o que permitiu uma taxa de lucro extraordinário (ganhos acima da concorrência plena) no ponto $\mathrm{X}$ da curva da demanda efetiva (DE). Isto é, as receitas advindas de cada demanda superam os custos de expansão da capacídade, resultado esse que induz a expansão da planta para Q2:

Receita total: $\mathrm{R} 1=\mathrm{P}(\mathrm{X}) \cdot \mathrm{Q} 1=\mathrm{P} 11 \cdot \mathrm{Q} 1(1 / 3)+\mathrm{P} 21 \cdot \mathrm{Q} 2(2 / 3)$

Custo total: $\mathrm{Cl}=(\mathrm{b}+\mathrm{B})$. Q1

Já no caso da existência da planta 2 fica claro que no ponto $Y$ da curva de demanda efetiva (DE) o preço de demanda $\mathrm{P}(\mathrm{Y})$ iguala-se ao custo marginal da expansão $\mathrm{CMgL}$, onde instala-se o equilíbrio competitivo com eficiência econômica, ou seja, receita igual à despesa e o lucro é apenas normal, indicando que o nível de capacidade é ótimo:

Receita total: $\mathrm{R} 2=\mathrm{P}(\mathrm{Y}) . \mathrm{Q} 2=\mathrm{P} 12 \cdot \mathrm{Q} 2(1 / 3)=\mathrm{P} 22 \cdot \mathrm{Q} 2(2 / 3)$

Custo total : $\mathrm{C} 2=(\mathrm{b}+\mathrm{B}) \cdot \mathrm{Q} 2$

A análise dessa natureza se complicaria muito com hipóteses de plantas indivisíveis e custos crescentes de produção e de expansão de capacidade, sem todavia introduzir novas conclusões; apenas no último caso estar-se-ia falando num lucro extraordinário que fatalmente seria apropriado pelos fatores de produção mais excassos, isto é, de oferta inelástica no longo prazo. Novamente está-se referindo aos atributos naturais e/ou culturais dificilmente reproduzíveis. Na ausência de uma definição do direito de propriedade, estas vantagens acabam sendo internalizadas pelos proprietários dos imóveis, prefeitura, negociantes etc. Esses aspectos distributivos da questão são os mais cifíceis de serem analisados teórica e empiricamente e, em certas circunstâncias, podem ter muito a ver com as variações ou mesmo com os níveis de preços nos respectivos locais receptores do turismo.

As múltiplas soluções nesse mercado dos equipamentos da infra-estrutura turística podem garantir uma alocação ótima de recursos 
no longo prazo, se os preços em cada uma das estaçōes turísticas forem adequadamente fixados, caso contrário as ineficiências de curto prazo permanecerão, com muito maior probabilidade no caso de expansão de capacidade a partir de plantas inđivisíveis.

\section{SUMÁRIO DAS CONCLUSÕES}

A proporção do consumo das atividades do turismo é relativamente pequena em relação ao consumo total, exceto nas atividades diretamente ligadas ao próprio fim do turismo. A alta elasticidade da oferta dos produtos geograficamente comercializáveis impede diferenças nos custos de vida e processos inflacionários nos centros turísticos, mesmo com demandas estacionais. A situação já não é tão tranquila quando a demanda pressiona a oferta dos equipamentos ligados à infra-estrutura, cuja oferta disponível, se for insuficiente gera alta de preços, se for mais que suficiente gera ineficiência alocativa pela ociosidade. Esse último caso é mais peculiar na presença da expansão da oferta a partir de plantas indivisíveis. Se também vigorar a expansão a custos crescentes, fatalmente os efeitos distributivos da apropriação dos benefícios e custos derivados da formação dos preços nas atividades turísticas poderá gerar ruídos inflacionários. As últimas palavras consistem em dizer que algumas pressões inflacionárias sentidas nos centros turísticos decorrentes da demanda de "pico" não devem ser entendidas como tendências permanentes, mas sim como efeitos meramente sazonais; o contrário podendo ocorrer nas épocas de baixa estação turísticas.

Por fim, em se tratando de um texto basicamente teórico, muitas de suas hipóteses deveriam ser empiricamente testadas.

\section{BIBLIOGRAFIA}

1. HIRSHLEIFER. J. Price thcon and applications. Prentice Hall, 1958.

2. MUSGRAVE. R.P. Finanças puiblicas: teoria e prática. Rio de Janeiro. Campus. 1980.

3. MUSKIN. S. Public enterprice. In: WILLIANSON, O. E. Peak-load pricing, 1981. 